\title{
Variabilidade espacial da resistência do solo à penetração e produtividade do milho
}

\section{Fabricio Justino da Silva ${ }^{1}$, Carlos Alberto Alves de Oliveira ${ }^{1}$, Leandro da Silva Almeida ${ }^{2}$, Leomar Paulo de Lima ${ }^{1}$, Ednaldo Carvalho Guimarães ${ }^{2}$}

\author{
${ }^{1}$ Instituto Federal do Triângulo Mineiro, Campus Uberlândia, Uberlândia, Minas Gerais, Brasil. E-mail: \\ fabriciojustinoagro@hotmail.com, carlosoliveira@iftm.edu.br, leomar@iftm.edu.br \\ ${ }^{2}$ Universidade Federal de Uberlândia, Uberlândia, Minas Gerais, Brasil. E-mail: almeidalean26@ gmail.com, ecg@ufu.br
}

Recebido: 05/05/2017; Aceito: 10/08/2017

\section{RESUMO}

O presente trabalho teve como objetivo estudar a variabilidade espacial da resistência do solo à penetração (RP), teor de água no solo (U) e a produtividade na cultura do milho. O experimento foi conduzido no ano agrícola de 2015/2016, na fazenda Sobradinho em Uberlândia -MG. A resistência à penetração foi determinada através do penetrômetro de impacto (modelo IAA/Planasulcar-Stolf) nas profundidades de 0-10 cm, 10-20 cm e 20-30 cm, Para analisar as variáveis, utilizou-se cálculos da estatística descritiva e técnicas de geoestatística. Para avaliar a dependência espacial das variáveis empregou-se o cálculo da semivariância e do ajuste dos dados ao semivariograma experimental. Para cálculo da produtividade foram colhidas as espigas, em condições de umidade de campo, em $2 \mathrm{~m}^{2}$ em cada ponto georeferenciados. As variáveis produtividade, RP10 e umidade apresentaram efeito pepita puro, ou seja, se comportaram de forma aleatória na área, de outro modo a resistência de solo à penetração nas camadas de $10-20 \mathrm{~cm}$ e $20-30 \mathrm{~cm}$ apresentaram moderada dependência espacial com um alcance prático de $58,3 \mathrm{~m}$. Ainda foi observado que o sistema de cultivo favoreceu a formação de uma camada subsuperficial mais compactada que a camada superficial.

Palavras-chave: Zea mays, geoestatistica, agricultura de precisão, umidade do solo

\section{Spatial variability of soil resistance to penetration and productivity of maize}

\begin{abstract}
The present work was to study the spatial variability of soil penetration resistance (RP), water content in the soil (U) and productivity in corn. The experiment was conducted in the agricultural year 2015/2016 in Sobradinho farm in Uberlândia-MG. The penetration resistance was determined by the impact penetrometer (IAA model / Planasulcar-Stolf) in $0-10 \mathrm{~cm}, 10-20 \mathrm{~cm}$ and $20-30 \mathrm{~cm}$, to analyze the variables, we used descriptive statistics calculations and geostatistic techniques. To evaluate the spatial dependence of the variables we used the calculation of semivariance and fitting the data to the experimental semivariogram. To calculate yield, the ears were harvested in $2 \mathrm{~m}^{2}$ at each point georeferenced. The variables, productivity, RP10 and soil moisture had pure nugget effect, that is, they behaved randomly in the area. The soil penetration resistance in the layers of 10-20 cm and 20-30 cm presented moderate spatial dependence with a practical reach of $58.3 \mathrm{~m}$
\end{abstract}

Key words: Zea mays, geoestistics, precision farming, soil moisture. 


\section{Introdução}

A cultura do milho (Zea mays L.) é, atualmente, a segunda maior cultura agrícola do Brasil, em termos de área cultivada e em produção de grãos. Na safra 2016/2017, a área colhida foi de mais de 17 milhões de hectares, com uma produção de 91.468,4 mil toneladas e produtividade média de $5.356 \mathrm{~kg} \mathrm{ha}^{-1}(\mathrm{CONAB}$, 2017).

Em decorrência da modernização da agricultura nas últimas décadas, surge a preocupação com a compactação do solo ocasionada pelo tráfego de máquinas e implementos que modificam os atributos do solo resultando na redução da disponibilidade de água e oxigênio e aumento da resistência do solo ao crescimento radicular, fator que dificulta a exploração em profundidade das raízes no solo ocasionando perdas na produtividade (BEUTLER et al., 2001). Klein et al. (2013) relatam que a compactação é uma das maiores causas da degradação de solos agrícolas resultando em sérias consequências sobre o desenvolvimento das plantas.

Os atributos físicos do solo, como densidade e resistência à penetração, têm sido avaliados para determinar a presença de camadas compactadas atuando como indicadores de restrição ao crescimento radicular (MARIA et al., 1999). Segundo Torres et al. (2015) o monitoramento dos atributos físicos do solo no início e após as atividades agrícolas em determinada área são ferramentas imprescindíveis ao planejamento das práticas de cultivo a serem adotadas pois estes atributos, quando avaliados continuamente, permitem monitorar a eficiência do sistema de manejo adotado.

A perda da qualidade física do solo implica em condições desfavoráveis à estruturação do solo como formação de agregados pouco estáveis, elevada densidade, maior resistência à penetração das raízes e resulta em condições que restringem o desenvolvimento e produção das culturas vegetais bem como a preservação dos recursos naturais (LIMA et al., 2013).

Por sua vez, monitorar estes atributos no solo não é questão simples, pois estes se constituem de uma complexa interação de fatores pedogenéticos, seu material de origem não é uniforme; possuem diferenças em relação à dureza, composição química e cristalização, sendo também influenciados pelas condições de clima e relevo, resultando assim na variabilidade espacial de seus atributos (MATIAS et al., 2015). O manejo antrópico é outro fator que contribui para a variabilidade espacial dos atributos do solo. $\mathrm{O}$ manejo no local específico é a base da agricultura de precisão; tem o objetivo de aumentar a eficiência do processo produtivo por meio de técnicas agrícolas conforme a variabilidade espacial dos atributos do solo (GIRARDELLO et al., 2014).
Por meio da agricultura de precisão tem-se o conhecimento da variabilidade existente no solo (AP), tornando possível identificar, nas áreas cultivadas, as zonas com restrições físicas, químicas e biológicas. (MATIAS et al., 2015). A AP permite ainda planejar atividades de recuperação e até mesmo aplicação de insumos agrícolas de acordo com a necessidade do solo, no local e quantidade adequados (ZANÃO JUNIOR et al., 2010). Esta variabilidade espacial e temporal pode ser estudada aplicando-se os princípios da geoestatística que permite identificar áreas carentes de insumos que podem limitar a produção (MARASCA et al., 2011; MATIAS et al., 2015).

Diante do exposto o presente trabalho teve como objetivo modelar a variabilidade espacial da resistência do solo à penetração (RP) em diferentes profundidades; da umidade (U) no perfil 0-30 $\mathrm{cm}$ e da produtividade da cultura do milho nesta área.

\section{Material e Métodos}

O experimento foi conduzido durante a safra de verão do ano agrícola de 2015/2016, na área da Fazenda Sobradinho, pertencente ao Instituto Federal de Educação, Ciência e Tecnologia do Triângulo Mineiro, Campus Uberlândia, situada no município de Uberlândia, MG, cujas coordenadas geográficas são: $18^{\circ} 45^{\prime} 53^{\prime \prime}$ de latitude sul e $-48^{\circ} 17^{\prime} 20^{\prime \prime}$ de longitude oeste e altitude média de 660 metros.

O clima da região segundo classificação climática de Köppen (1948) é do tipo Cwa caracterizado como clima tropical com inverno seco e verão chuvoso, temperatura média de $21,5^{\circ} \mathrm{C}$ e precipitação anual em torno de 1600 $\mathrm{mm}$ com períodos de seca e chuva bem definidos. A vegetação nativa da área é cerrado arbóreo-arbustivo, porém a área de instalação do experimento tem sido utilizada na pecuária por 15 anos. O solo da área é um Latossolo Vermelho- Amarelo Distrófico típico (EMBRAPA, 2013) de textura argilosa.

Foi semeado 1 hectare de milho no dia 16/11/2015 adotando a prática de plantio direto utilizando a variedade de milho LG 6304 PRO, com espaçamento de $0,90 \mathrm{~m}, 6$ sementes por metro para obter uma população de 62 mil plantas por hectare.

Para a caracterização física do solo, a área experimental foi dividida numa malha não sistemática, com 50 pontos georreferenciados. Dentro da área de abrangência de cada ponto da malha foram realizadas 7 avaliações para compor média do ponto determinando o teor de água no solo (U) para a camada de $0-30 \mathrm{~cm}$ e a resistência do solo à penetração (RP), até a profundidade de $30 \mathrm{~cm}$, estratificada nas camadas de $0,00-10 ; 10-20$ e $20-30 \mathrm{~cm}$. A resistência à penetração (RP) foi determinada através do penetrômetro de impacto (modelo IAA/Planasulcar-Stolf) de acordo com 
método descrito por Stolf et al. (1983). Os dados obtidos serão transformados em RP com o uso da fórmula proposta por Stolf (1991), Equação 1:

$$
R P=\left[\frac{M g+m g+\left(\frac{M}{M+m} \times \frac{M g x h}{x}\right)}{A}\right] x ।
$$

onde: RP- Resistência do solo à penetração (MPa); M-Massa do êmbolo, 4 kg (Mg- 4 kgf); m- Massa do aparelho sem êmbolo, 3,2 kg (mg - 3,2 kgf); gAceleração da gravidade; h- Altura de queda do êmbolo $(40 \mathrm{~cm}) ; \mathrm{x}$ - Penetração da haste do aparelho, cm/impacto; A - área da base do cone de penetração (cm2).

A umidade do solo (U) que representa o teor de água no solo foi obtida pelo método gravimétrico, de acordo com parâmetros da Embrapa (1997). Para determinação do teor de umidade do solo procedeu-se da seguinte maneira: foram colocadas amostras em latas de alumínio, numeradas, pesadas e transferidas para estufa a $105^{\circ} \mathrm{C}$ por 24 horas, em seguida foram passadas para o dessecador para esfriamento, posteriormente pesadas e então efetuado o cálculo, Equação 2:

$$
\mathrm{U}=100 \frac{(a-b)}{b}
$$

onde: U - umidade do solo em \%; a - peso da amostra úmida $(\mathrm{g}) ; \mathrm{b}$ - peso da amostra seca $(\mathrm{g}) ; \mathrm{c}$ volume da amostra $\left(\mathrm{cm}^{3}\right)$

A produtividade do milho foi obtida pela coleta de espigas nos pontos georreferenciados (50 pontos) em uma área de $2 \mathrm{~m}^{2}$, o milho posteriormente foi debulhado, pesado, corrigido o teor de água para $13 \% \mathrm{e}$ extrapolado para a produtividade $\mathrm{kg} \mathrm{ha}^{-1}$.

Os dados obtidos de RP foram classificados de acordo com a Tabela 1, na qual são apresentadas as classes de resistência do solo à penetração adaptadas e citadas por Beutler et al. (2001):

Tabela 1. Classes de resistência do solo à penetração ${ }^{(1)}$

\begin{tabular}{lc}
\hline \multicolumn{1}{c}{ Classe } & $\begin{array}{c}\text { Resistência à penetração } \\
(\mathrm{MPa})\end{array}$ \\
\hline Extremamente baixa & $<0,01$ \\
Muito baixa & $0,01-0,1$ \\
Baixa & $0,1-1,0$ \\
Moderada & $1,0-2,0$ \\
Alta & $2,0-4,0$ \\
Muito alta & $4,0-8,0$ \\
Extremamente alta & $>8,0$ \\
${ }^{(1)}$ Fonte: Beutler et al. (2001).
\end{tabular}

Após a obtenção dos dados de RP, U e produtividade, procedeu-se às análises por meio da estatística descritiva e de técnicas de geoestatística para estudar as influências destas variáveis na cultura do milho.

Para avaliar a dependência espacial das variáveis foi empregado o cálculo da semivariância e do ajuste dos dados ao semivariograma experimental (GREGO; VIEIRA, 2005). Os semivariogramas são representações gráficas, nos quais a semivariância $\gamma(\mathrm{h})$ representada na coordenada y, em função de uma determinada distância $h$, representada no coordenada x (MARASCA et al., 2011). O que pode ser estimado pela Equação 3:

$$
\gamma(\mathrm{h})=\frac{1}{2 N(h)} \sum_{\mathrm{i}=1}^{\mathrm{N}(\mathrm{h})}\left[\mathrm{Z}\left(\mathrm{x}_{\mathrm{i}}\right)-\mathrm{Z}\left(\mathrm{x}_{\mathrm{i}}+\mathrm{h}\right)\right.
$$

onde, $N(h)$ representa o número de pares de valores medidos, $Z(x i)$ e $Z(x i+h)$, separados por um vetor $(h)$. O gráfico de $\gamma(\mathrm{h})$ versus os valores correspondentes de $h$ é denominado semivariograma.

Após o ajuste do modelo teórico do semivariograma, avaliou-se o grau de dependência espacial (Equação 4), conforme proposto por Cambardella et al. (1994).

$$
G D=\frac{C o}{C o+C}
$$

Onde: $\mathrm{GD}=$ grau de dependência espacial; $\mathrm{Co}=$ Efeito Pepita; $\mathrm{C}=$ contribuição $(\mathrm{Co}+\mathrm{C}=$ patamar $)$.

Sendo: GD $<0,25$ Forte; $\geq 0,25$ GD $\leq 0,75$ Moderada; e, GD > 0,75 Fraca

Após estas verificações para os atributos do solo que apresentaram dependência espacial aplicou-se a krigagem ordinária para a interpolação (YAMAMOTO; LANDIM, 2013). Quando os atributos não apresentaram dependência espacial, ou seja, apresentaram efeito pepita puro, estes foram interpolados pelo método do inverso do quadrado das distâncias, que, conforme estudo realizado por Krajewski e Gibbs (2001), é o método de interpolação por estatística clássica mais assertivo. As análises dos resultados foram procedidas com o auxílio do programa $\mathrm{R}$ versão 3.2.1 ( $\mathrm{R}$ DEVELOPMENT CORE TEAM, 2015), utilizando o pacote de dados geoR.

\section{Resultados e Discussão}

Os valores médios de RP nas profundidades de 0-10; 10-20 e 20-30 foram 4,01; 5,18 e 5,12 MPa, respectivamente (Tabela 2). De acordo com a classificação de Beutler et al. (2001), os valores de RP nas três profundidades são muito altos (Tabela 1), no entanto estão em consonância com valores obtidos por Torres et al. (2015) e Silva et al. (2009) que determinam como faixa limite de compactação a resistência em torno de 6,5 Mpa, valor que já causa severas restrições ao desenvolvimento radicular em diversas culturas. 
Tabela 2: Estatística descritiva da resistência a penetração do solo em três profundidades, da umidade do solo e da produtividade do milho.

\begin{tabular}{|c|c|c|c|c|c|c|c|}
\hline Fator & Unid & Mínimo & Média & Mediana & Máximo & $\begin{array}{l}\text { Desvio } \\
\text { Padrão }\end{array}$ & $\begin{array}{l}\text { Coeficiente } \\
\text { de variação }\end{array}$ \\
\hline Prod $^{1}$. & $\mathrm{Kg} \mathrm{ha}^{-1}$ & 3424,80 & 6629,44 & 6612,60 & 10747,97 & 1668,99 & 25,17 \\
\hline $\mathrm{RP} 10^{2}$ & Mpa & 2,51 & 4,01 & 3,93 & 5,35 & 0,70 & 17,52 \\
\hline $\mathrm{RP} 20^{2}$ & Mpa & 3,81 & 5,18 & 5,17 & 6,53 & 0,64 & 12,44 \\
\hline $\mathrm{RP} 30^{2}$ & Mpa & 3,22 & 5,12 & 5,05 & 6,77 & 0,68 & 13,28 \\
\hline Umidade & $\%$ & 21,50 & 30,65 & 30,85 & 35,10 & 1,78 & 5,80 \\
\hline
\end{tabular}

${ }^{-1}$ Produtividade em kg/ha; ${ }^{2}$ Resistência do solo à penetração nas camadas de 0-10, 10-20 e 20-30cm.

O coeficiente de variação (CV) oscilou entre 5,8 e $25,17 \%$, sendo estes valores marginais observados para a umidade do solo e produtividade respectivamente (Tabela 2). Adotando o critério de classificação proposto por Warrick e Nielsen (1998) a variável produtividade é classificada como uma variação média e os demais atributos classificados como baixa variabilidade. Esta classificação do coeficiente de variação de Warrick e Nielsen (1998) propõe os seguintes limites: $\mathrm{CV}<15 \%$ este é baixo, médio para o intervalo de $15 \% \leq \mathrm{CV}<50 \%$ e alta variabilidade quando $\mathrm{CV} \geq 50 \%$. Um alto coeficiente de variação segundo Carvalho et al. (2003) é esperado quando os dados apresentam grande amplitude nos valores conforme, o que não acontece como se revela os valores de mínimo e máximo (Tabela 2). Destaca-se ainda que as estatísticas média e mediana possuem valores próximos entre si ocorrendo uma tendência simétrica na distribuição dos dados; de acordo com Yamamoto e Landim (2013), para aplicação do estimador de Matheron (Equação 3) é recomendável que a variável não apresente assimetria acentuada.

Observa-se para a resistência a penetração na primeira camada, na profundidade de $0-10 \mathrm{~cm}$ com menor resistência à penetração (Tabela 2), ou seja, menos compactada, o que é justificado pela presença de sistema radicular das plantas e da atividade biológica do solo (SANTOS et al., 2015). Nas camadas com profundidade de $10-20$ e $20-30 \mathrm{~cm}$, a resistência à penetração é maior, fato que pode ser justificado pelo sistema de cultivo cuja área é utilizada para preparação de silagem, colocando gado em seguida. Desta forma, a presença de equipamentos agrícolas e o pisoteio dos animais, ocasionam a formação de uma camada subsuperficial compactada, fato que corrobora com os resultados obtidos por Santos et al. (2015) que também observaram o efeito da compactação do solo pelo pisoteio dos animais.

$\mathrm{Na}$ análise descritiva espacial foram elaborados os mapas de distribuição dos elementos na área do estudo e também realizada a verificação de tendência dos dados nas direções leste (x) e norte (y) e o histograma do conjunto de dados (Figura 1).
A estatística do quartil (Q1, Q2 e Q3) e os gráficos de dispersão possibilitam verificar se os atributos do solo apresentam distribuição concentrada em algum ponto da área em estudo. Segundo, Soares (2006) a tendência não inviabiliza a análise geoestatística, entretanto seria necessária transformação dos dados para executar a análise. Observe na Figura 3 que os quartis estão distribuídos em toda a área e os gráficos de dispersão dos valores em relação a $\mathrm{X}$ e em relação a $\mathrm{Y}$ não indicam ocorrer tendência significativa nos dados.

Os histogramas mostram, nesses casos, que não ocorre assimetria acentuada para essas variáveis indicando assim a viabilidade da aplicação da metodologia de análise geoestatística utilizando o estimador de Matheron (VIEIRA et al., 1983). Foram ajustados os modelos de semivariograma (Figura 2), a sentimento e selecionados os que apresentaram melhores parâmetros baseados na validação cruzada (Tabela 3).

As variáveis, produtividade, RP10 e umidade apresentaram efeito pepita puro, ou seja, não apresentaram dependência espacial, sendo impraticável o ajuste ao modelo de semivariograma. É justificável pelo fato da menor distância da malha não ser suficiente para quantificar a sua dependência espacial (LIMA et al., 2010); em condições experimentais semelhantes ao presente estudo, Souza et al. (2004) encontraram dependência espacial para a umidade do solo, no entanto, os autores utilizaram uma malha sistemática de 100 pontos por hectare, ou seja, o dobro da malha utilizada no presente estudo.

A umidade não apresentou dependência espacial, talvez pelo teor elevado de água encontrado no solo em decorrência da precipitação próxima ao dia de coleta. Estes resultados corroboram aos obtidos por Marasca et al. (2011) em estudo da variabilidade espacial da resistência do solo à penetração com decorrência de chuva durante o período de coleta.

A avaliação de RP expressa por meio dos semivariogramas apresentou dependência espacial nas profundidades de $10-20 \mathrm{~cm}$ e $20-30 \mathrm{~cm}$ sendo ambos ajustados no modelo exponencial e em ambas as profundidades apresentando grau de dependência espacial moderada de 0,46 e 0,44 respectivamente. 

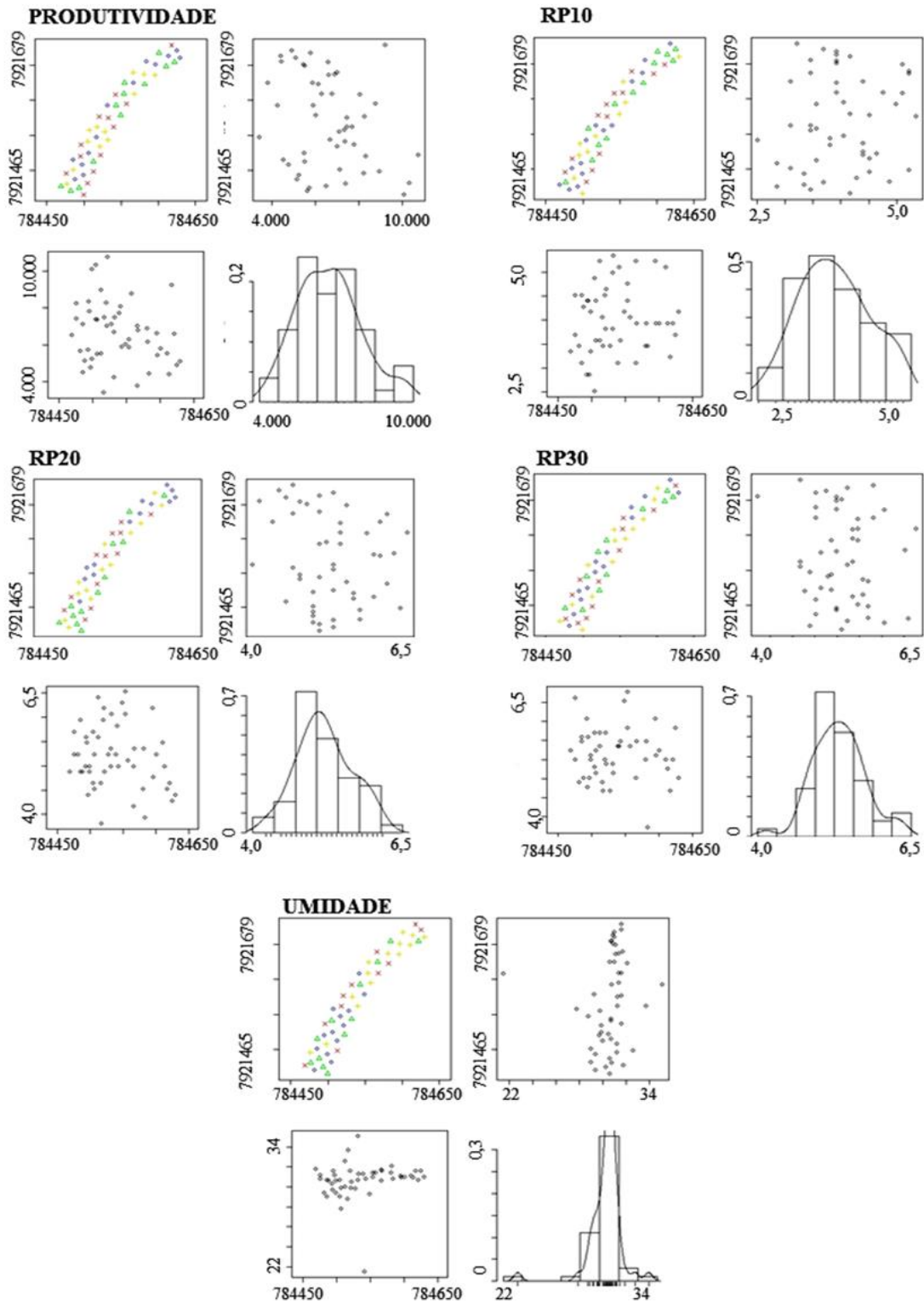

Figura 1. Gráficos de posição dos pontos amostrados de acordo com os quartis (classes definidas na sequência de tamanhos das representações: Min |-- Q1; Q1 |-- Q2; Q2 |-- Q3; Q3 |-- Max). Dispersão sentido x e y e histograma da produtividade da resistência a penetração nas três profundidades e da umidade do solo.
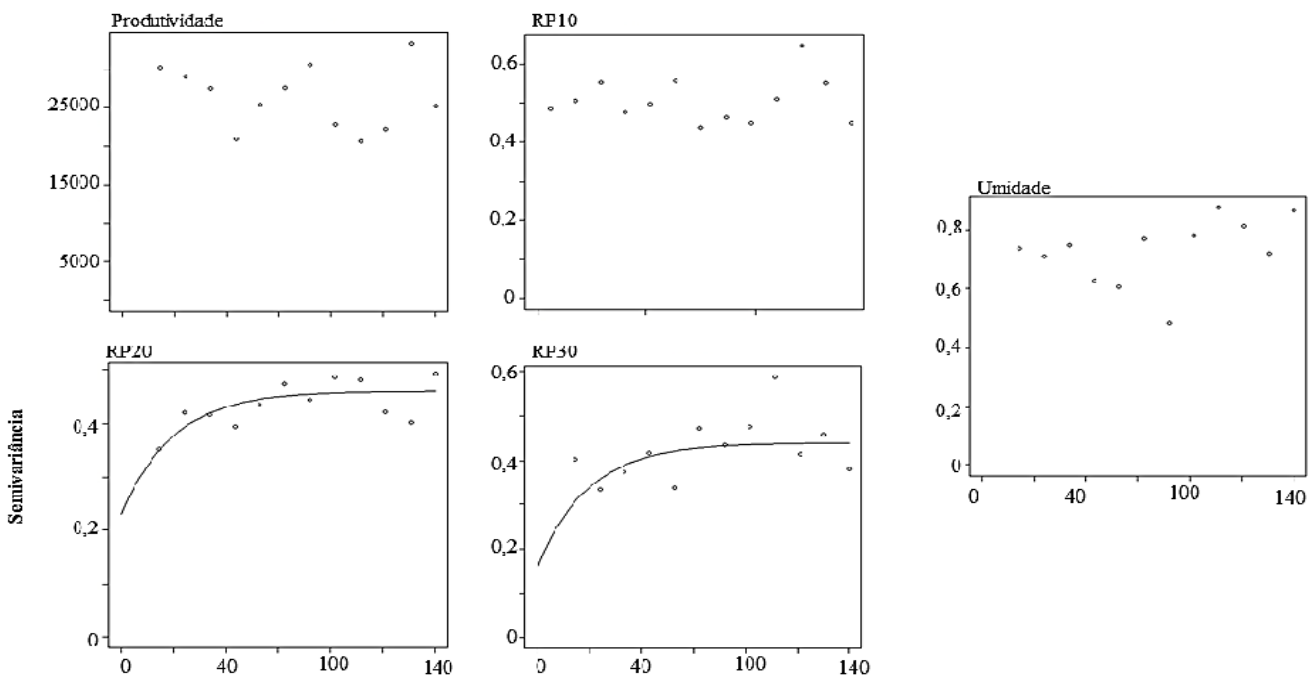

Distancia (m)

Figura 2. Semivariograma ajustado para a produtividade do milho, resistência do solo a penetração em três profundidades e umidade do solo. 
Tabela 3. Modelos, parâmetros, relação $\mathrm{Co} /(\mathrm{Co}+\mathrm{C})$ e grau da dependência espacial dos semivariogramas ajustados para a produtividade a RP nas três profundidades e a umidade do solo.

\begin{tabular}{lclcccc}
\hline \multicolumn{1}{c}{ Atributo } & Modelo & $\mathrm{C}_{0}{ }^{1}$ & Alcance teórico & Alcance Prático & $\mathrm{Co} /(\mathrm{Co}+\mathrm{C})^{1}$ & $\mathrm{GD}^{2}$ \\
\hline Produtividade & $\mathrm{EPP}^{3}$ & ---- & ---- & --- & --- \\
RP10 & $\mathrm{EPP}^{3}$ & --- & --- & --- & --- \\
RP20 & Exponencial & 0,23 & 19,47 & 58,33 & 0,46 & Moderado \\
RP30 & Exponencial & 0,16 & 19,47 & 58,33 & 0,44 & Moderado \\
Umidade & EPP $^{3}$ & ---- & ---- & ---- & --- \\
\hline Co $=$ efeito pepita; C $=$ contribuição; Co $+\mathrm{C}=$ patamar; ${ }^{1}$ método de Cambardella et al. $(1994) ;{ }^{2} \mathrm{GD}=$ Grau de dependência; ${ }^{3} \mathrm{EPP}=$ efeito pepita puro.
\end{tabular}
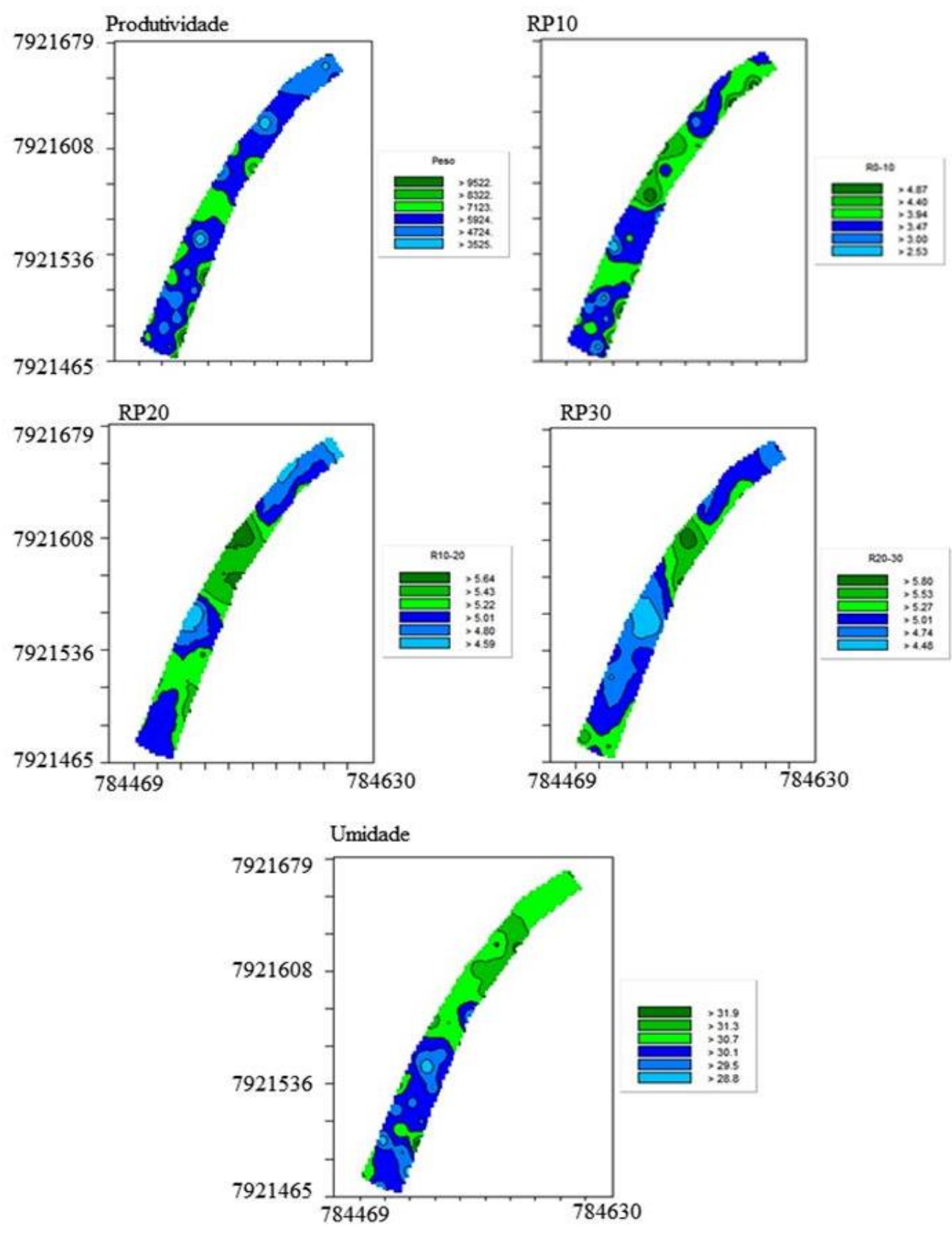

Figura 3. Mapas de padrões espaciais ajustados para a produtividade a RP nas três profundidades e a umidade do solo.

O alcance prático e teórico da RP à penetração foram idênticos para as profundidades de $10-20 \mathrm{~cm}$ e 20-30 cm (Tabela 3), mostrando assim o mesmo comportamento na área deste atributo nas duas profundidades.
O alcance de dependência espacial é um parâmetro importante no estudo do semivariograma e define a distância máxima que uma variável está correlacionada espacialmente. Neste estudo foi verificado que RP20 e RP30 apresentaram alcance de 58,33, informação que 
garante que todos os vizinhos situados dentro de um círculo com esse raio são tão similares que podem ser usados para estimar valores para qualquer ponto entre eles (SALVIANO et al., 1998).

Os mapas de padrões espaciais da RP20 e RP30 foram gerados por krigagem ordinária e os demais pelo inverso do quadrado das distâncias (Figura 3). Os mapas de padrões espaciais da produtividade e RP e umidade (Figura 3), mostram grande heterogeneidade na área ressaltando assim a importância de planejar as atividades de maneira diferenciada.

Ao mapear as áreas que necessitam de maiores cuidados naquele momento viabiliza-se uma gestão mais eficiente de recursos que busca maior eficiência produtiva. Nos tempos atuais é necessário que o agricultor busque maximizar a interação entre os fatores que influenciam o seu rendimento e desenvolvimento visando aumentar os níveis de produtividade de forma sustentável. A agricultura de precisão é uma ferramenta que tem sido utilizada para quantificar e modelar a variabilidade espacial e temporal dos fatores ligados às interações solo-água-planta, visando aperfeiçoar o uso de insumos agrícolas ao realizar a distribuição adequada em cada setor do campo de produção, além de trazer benefícios ambientais (MOLIN; CASTRO, 2008).

Autores têm observado que os atributos de solo muitas vezes não revelam uma variação puramente aleatória ao longo de um terreno, apresentando correlação espacial (ALMEIDA; GUIMARÃES, 2016; GOMES et al., 2007; ZANÃO JÚNIOR et al 2010). Assim, a geoestatística tem sido utilizada como importante ferramenta de análise dos dados, a fim de modelar e estudar a estrutura de dependência espacial dos atributos do solo, por meio do ajuste de semivariogramas experimentais (MANZIONE; ZIMBACK, 2011).

Os resultados revelam a importância de intensificar os estudos da variabilidade espacial dos atributos do solo para conhecer o seu comportamento no sistema solo-planta; neste estudo, em um solo com uma resistência à penetração alta, observa-se grande diferença dos resultados obtidos. Há necessidade de mais estudos em diferentes condições de solo, clima e manejo para se entender mais sobre os benefícios da variabilidade espacial dos atributos do solo e sua influência no sistema produtivo.

\section{Conclusões}

O sistema de cultivo favoreceu a formação de uma camada subsuperficial mais compactada que a camada superficial.

As variáveis, produtividade, RP10 e umidade apresentaram efeito pepita puro, ou seja, se comportaram de forma aleatória na área.
A resistência do solo à penetração nas camadas de $10-20 \mathrm{~cm}$ e $20-30 \mathrm{~cm}$ apresentaram moderada dependência espacial com um alcance prático de 58,3 m.

\section{Referências Bibliográficas}

ALMEIDA, L. S.; GUIMARÃES, E. C. Geoestatística e análise fatorial exploratória para representação espacial de atributos químicos do solo, na cafeicultura. Coffee Science, Lavras-MG, v. 11, n. 2, p. 195-203, 2016. Disponível em: << http://www.coffeescience.ufla.br/index.php/Coffeescience/arti cle/view/1041 >. Acesso em: 05 maio 2017.

BEUTLER, A. N.; SILVA, M. L. N.; CURI, N.; FERREIRA, M. M.; CRUZ, J. C.; PEREIRA FILHO, I. A. Resistência à penetração e permeabilidade de Latossolo Vermelho distrófico típico sob sistemas de manejo na região dos cerrados. Revista Brasileira de Ciência do Solo. Viçosa-MG, v. 25, n. 1, p. 167-177, 2001. Disponível em: < http://ainfo.cnptia.embrapa.br/digital/bitstream/item/50677/1/ Resistencia-penetracao.pdf $>$. Acesso em: 05 maio 2015.

CAMBARDELLA, C. A.; MOORMAN, T. B.; NOVAK, J. M.; PARKIN, T. B.; KARLEN, D. L.; TURCO, R. F.; KONOPKA, A. E. Field-scale variability of soil proprieties in central Iowa soils. Soil Science Society America Journal, Madison, v. 58, n. 5, p.1240-1248, 1994.

CARVALHO, M. P.; TAKEDA, E. Y.; FREDDI, O. S. Variabilidade espacial de atributos de um solo sob videira em Vitória Brasil (SP). Revista Brasileira de Ciência do solo. Viçosa-MG, v. 27, n. 4, p. 695-703, 2003.

CONAB. COMPANHIA NACIONAL DE ABASTECIMENTO. Acompanhamento safra brasileira de grãos, v. 6- Safra 2016/2017 - Sexto levantamento, BrasíliaDF: CONAB, 2017. p. 1-140. Disponível em: <http://www.conab.gov.br/>. Acesso em: 20 abr. 2017.

EMBRAPA. EMPRESA BRASILEIRA DE PESQUISA AGROPECUÁRIA. Sistema Brasileiro de Classificação de Solos. 3. ed. Brasília-DF: Embrapa, 2013. 353 p.

EMBRAPA. EMPRESA BRASILEIRA DE PESQUISA AGROPECUÁRIA. Manual de métodos de análise de solo. Rio de Janeiro-RJ: Ministério da Agricultura e do Abastecimento, 1997. 212 p.

GIRARDELLO, V. C.; AMADO, T. J. C.; SANTI, A. L.; CHERUBIN, M. R.; KUNZ, J.; TEIXEIRA, T. G. Resistencia à penetração, eficiência de escarificadores mecânicos e produtividade da soja em latossolo argiloso manejado sob plantio direto de longa duração. Revista Brasileira de Ciência do Solo, Viçosa-MG, v. 38, n. 4, p. 1234-1244, 2014.

GOMES, N. M.; FARIA, M. A.; SILVA, A. M.; MELLO, C. R.; VIOLA, M. R. Variabilidade espacial de atributos físicos do solo associados ao uso e ocupação da paisagem. Revista Brasileira de Engenharia Agrícola e Ambiental, Campina Grande-PB, v. 11, n. 4, p. 427-435, 2007.

GREGO, C. R.; VIEIRA, S. R. Variabilidade espacial de propriedades físicas do solo em uma parcela experimental. Revista Brasileira de Ciência do Solo, Viçosa-MG, v. 29, n. 2, p. 169-177, 2005. 
KRAJEWSKI, S. A.; GIBBS, B. L. Uderstanding contouring: a pratical guide to spatial estimation using computer and variogram interpretation. Boulder, CO: Gibbs Associations, 2001. $100 \mathrm{p}$

KLEIN, V. A.; MADALOSSO, T.; BASEGGIO, M. Ensaio de Proctor normal-análise metodológica e planilha para cálculo da densidade do solo máxima e teor de água ótimo. Revista de Ciências Agroveterinárias, Lages-SC, v. 12, n. 2, p. 199203, 2013. Disponível em: <http://revistas.bvsvet.org.br/rca/article/view/34858/39144>. Acesso em: 05 maio 2017.

KÖPPEN, W. Climatologia: con un estudio de los climas de la tierra. México: Fondo de Cultura Econômica, 1948. 479 p.

LIMA, J. S. S.; SOUZA, G. S.; SILVA, S. A. Amostragem e variabilidade espacial de atributos químicos do solo em área de vegetação natural em regeneração. Revista Árvore, Viçosa-MG, v. 34, n. 1, p. 127-136, 2010

LIMA, I. M. A.; ARAÚJO, M. C.; BARBOSA, R. S. Avaliação das propriedades físicas do solo em sistemas silvipastoris, região centro-norte, estado do Piauí. Agropecuária Científica no Semiárido, Campina GrandePB, v. 9, n. 1, p. 117-124, 2013. Disponível em: << http://revistas.ufcg.edu.br/acsa/index.php/ACSA/article/view/ 252>>. Acesso em: 05 maio 2017.

MANZIONE, R. L.; ZIMBACK, C. R. L. Análise Espacial Multivariada Aplicada na Avaliação da Fertilidade do Solo. Engenharia na Agricultura, Viçosa-MG, v. 19, n. 3, p. $227-$ 235, 2011. Disponível em: < http://www.seer.ufv.br/seer/index.php/reveng/article/view/181 /166>. Acesso em: 03 maio 2017.

MARASCA, I.; OLIVEIRA, C. A. A.; GUIMARÃES, E. C.; CUNHA, J. P. A. R.; ASSIS R. L.; PERIN, A.; MENEZES, L. A. S. Variabilidade espacial da resistência do solo à penetração e teor de água em sistema de plantio direto, na cultura da soja. Bioscience Journal, Uberlândia-MG, v. 27, n. 2. p. 239-246. 2011.

MARIA, I. C.; CASTRO, O. M.; SOUZA DIAS, H. Atributos físicos do solo e crescimento radicular de soja em Latossolo Roxo sob diferentes métodos de preparo do solo. Revista Brasileira de Ciência do Solo, Viçosa-MG, v. 23, n. 3, p. 703-709, 1999.

MATIAS, S. S. R.; NÓBREGA, J. C. A.; NÓBREGA, R. S. A.; ANDRADE, F. R.; BAPTISTEL, A. C. Variabilidade espacial de atributos químicos em Latossolo cultivado de modo convencional com soja no cerrado piauiense. Revista Agro@mbiente On-line, Boa Vista-RO, v. 9, n. 1, p. 17-26, 2015.

MOLIN, J. P.; CASTRO, C. N. Establishing management zones using soil electrical conductivity and other soil properties by the fuzzy clustering technique. Scientia Agricola, Piracicaba-SP, v. 65, n. 6, p. 567-573, 2008.

$\mathrm{R}$ DELOPMENT CORE TEAM. R: A language and environment for statistical computing. $\mathbf{R}$ Foundation for Statistical Computing, 2015. Viena: Disponível em: <http://www.r-project.org>. Acesso em: 18 jun. 2016.
SALVIANO, A. A. C.; VIEIRA, S. R.; SPAROVEK, G. Variabilidade espacial de atributos de solo e de Crotalaria juncea (L) em área severamente erodida. Revista Brasileira de Ciência do Solo, Viçosa-MG, v. 22, n. 1, p. 115-122, 1998.

SANTOS, M. H. F. RIBON, A. A.; FRENANDES, K. L.; SILVA, O. C. C.; OLIVEIRA, L. C.; SILVA, A. Estimativa da compactação através da resistência do solo à penetração em solo sob diferentes culturas e mata nativa. Revista Científica Eletrônica de Agronomia, Garça-SP, v. 14, n. 27, p. 49-62, 2015.

SILVA, J. M.; PASSOS, A. L. R.; BELTRÃO, F. A. S. Análise espacial da densidade, umidade e resistência mecânica do solo à penetração sob sistemas de cultivo. Engenharia Ambiental. Espírito Santo do Pinhal-SP, v. 6, n. 3, p. 103118,2009

SOARES, A. Geoestatística para ciências da terra e do ambiente. 2. ed. Lisboa: IST Press, 2006. 2014 p.

SOUZA, Z. M. MARQUES JÚNIOR, J.; PEREIRA, G. T.; BENTO, M. J. C. Variabilidade espacial de atributos físicos de um Latossolo Vermelho sob cultivo de cana-de-açúcar. Revista Brasileira de Engenharia Agrícola e Ambiental, Campina Grande-PB, v. 8, n. 1, p. 51-58, 2004.

STOLF, R.; FERNANDES, J.; FURLANI NETO, V. L. Recomendações para o uso do penetrômetro de impacto, modelo IAA/Planalsucar-Stolf. São Paulo-SP: MIC/IAA/PNMCA-Planalsucar, 1983. 8 p. (Boletim, 1).

STOLF, R. Teoria e teste experimental de fórmulas de transformação de dados de penetrômetro de impacto em resistência do solo. Revista Brasileira de Ciência do Solo, Campinas-SP, v. 15, n. 3, p. 229-235, 1991

TORRES, J. L. R.; COSTA, D. D. A; SILVA NETO, O. F.; ARAÚJO, A. S.; SILVA, V. R.; VIEIRA, D. M. S. Avaliação da resistência à penetração e densidade do solo num latossolo sob semeadura direta há doze anos. Global Science and Technology, Rio Verde-GO, v. 8, n. 1, p. 131-140, 2015.

VIEIRA， S. R.; HATFIELD, J. L.; NIELSEN, D. R.; BIGGAR, J. W. Geostatistical theory and application to variability of some agronomical properties. Hilgardia, Berkeley, v. 31, n. 3, p. 01-75, 1983.

WARRICK, A.W.; NIELSEN, D.R. Spatial variability of soil physical properties in the field. In: HILLEL, D. Environmental soil physics. New York: Academic, 1998. p. 655- 675 .

YAMAMOTO, J. K.; LANDIM, P. M. B. Geoestatística: conceitos e aplicações. São Paulo-SP: Oficina de Textos, 2013. $215 \mathrm{p}$.

ZANÃO JÚNIOR, L. A.; LANA, R. M. Q.; CARVALHOZANÃO, M. P.; GUIMARÃES, E. C. Variabilidade espacial de atributos químicos em diferentes profundidades em um Latossolo em sistema de plantio direto. Revista Ceres, Viçosa-MG, v. 57, n. 3, p. 429-438, 2010. 